\section{The role of revascularisation in the}

\section{management of non-ST elevation acute}

\section{coronary syndromes: who should you refer?}

R Andrew Archbold MD MRCP, Department of Cardiology, St Bartholomew's Hospital, London

Nicholas P Curzen PhD FRCP FESC, Wessex Cardiac Unit, Southampton University Hospital, Southampton

\section{Clin Med 2004:4:32-35}

Non-ST segment elevation (NSTE) acute coronary syndromes (ACS) account for the majority of coronary care unit admissions. Registry data from the UK reveal that six months after such an admission there is a $12.2 \%$ rate of death or non-fatal myocardial infarction (MI), and a $30 \%$ rate of death, MI, refractory angina or readmission to hospital for unstable angina. ${ }^{1}$ The pathophysiology of these syndromes is increasingly understood and is associated with improved targeting of medical therapy. ${ }^{2,3}$ Risk stratification is the foundation of the current strategy for early coronary angiography and revascularisation (either percutaneous or surgical) in patients with ACS, with the aim of detecting those known to be at higher risk of further events, including death, MI or readmission with further unstable symptoms. Markers of high risk have been discussed in an earlier article in this section.

In brief, the invasive cardiologist expects to be offered three categories of patients with NSTE ACS who should be referred for inpatient angiography and revascularisation because of their risk of further early events:

1 Patients with ongoing pain or ECG changes.

2 Patients with elevated troponin (Tn) levels (for example, ( $\mathrm{TnT}) \geqslant 0.05$ $\mathrm{ng} / \mathrm{ml})$.

3 Patients with ST depression on admission ECG.

What is the evidence that offering angiography and then revascularisation to patients in one of these high risk clinical categories provides them with a better outcome?

Several trials can be used to address this question. From the viewpoint of modern interventional cardiology, they may be divided into two groups: historical and contemporary. The relevance of the historical trials is dubious because they are so far away from modern clinical practice in terms of intervention (stents and drug-coated stents) and adjunctive pharmacological therapy (clopidogrel, glycoprotein (GP) IIb/IIIa inhibitors, statins, angiotensinconverting enzyme inhibitors). Even the contemporary studies provide only some indication of the potential benefit of the newer therapies available.

\section{TRIAL ACRONYMS}

\begin{tabular}{|c|c|}
\hline CAPTURE & Chimeric 7E3 Antiplatelet Therapy in Unstable Refractory Angin \\
\hline FRISC II & $\begin{array}{l}\text { Fragmin and Fast Revascularisation during InStability in } \\
\text { Coronary artery disease }\end{array}$ \\
\hline USTO IV & $\begin{array}{l}\text { Global Use of Streptokinase and Tissue Plasminogen Activator } \\
\text { for Occluded Arteries }\end{array}$ \\
\hline SAR-COOL & Intracoronary Stenting and Antithrombotic Regimen \\
\hline TA 3 & Randomized Intervention Trial of unstable Angina 3 \\
\hline ACTICS-TIMI 18 & $\begin{array}{l}\text { Thrombolysis and Counterpulsation to Improve Cardiogenic } \\
\text { Shock Survival-Thrombolysis in Myocardial Infarction } 18\end{array}$ \\
\hline NQWISH & Veterans Affairs Non-Q-Wave Infarction Strategies in Hospital \\
\hline
\end{tabular}

\section{The trial evidence}

There have been five major randomised controlled trials: TIMI IIIB, VANQWISH, FRISC II, TACTICS-TIMI 18 and RITA 3 (see box for explanation of acronyms). ${ }^{4-10}$ They all randomised patients with NSTE ACS to either early coronary angiography with revascularisation or an early conservative approach.

\section{Historical studies}

\section{TIMI IIIB}

Between 1989 and 1992, 1,473 patients were randomised in a $2 \times 2$ factorial design to tissue plasminogen activator or placebo as well as to an early invasive or conservative strategy. ${ }^{4}$ The primary endpoint of death, MI or symptom-limited exercise stress test at six weeks was reached in $16.2 \%$ patients in the invasive group and $18.1 \%$ in the conservative group $(p=0.33){ }^{4}$ The percentage of patients rehospitalised within six weeks was significantly lower in the invasive group ( $7.8 \%$ vs $14.1 \%, p<0.001)$. At one year, the incidence of death or MI was similar in the two groups $(10.8 \%$ vs $12.2 \%, p=0.4)$, although repeat hospital admissions remained significantly lower in patients in the invasive treatment group $(26 \%$ vs $33 \%, p<0.005) .^{5}$

\section{VANQWISH}

This trial included 920 patients with non- $Q$ wave MI. The primary end-point of death or non-fatal MI was reached in $29.9 \%$ patients randomised to the early invasive strategy and $26.9 \%$ patients in the conservative group $(p=0.35)$ at a mean of 23 months follow-up. ${ }^{6}$ Of note is the $12 \% 30$-day mortality associated with coronary artery bypass grafting.

\section{Contemporary studies}

\section{FRISC II}

In FRISC II, between 1996 and 1998 a total of 2,457 patients with NSTE ACS were randomly assigned to an early invasive or conservative strategy and to three months of either dalteparin or placebo using a factorial design. ${ }^{7}$ The 
patients treated invasively were revascularised within 10 days of randomisation, which itself occurred within 72 hours. The six-month primary outcome of death or MI was reached in $9.4 \%$ of patients in the early invasive group and $12.1 \%$ in the early conservative group $(p=0.031)$. Furthermore, at two-year follow-up, there was a significant absolute reduction of $4.2 \%(12.1 \%$ vs $16.3 \%)$ in the combined primary endpoint of death or MI in the early invasive group $(p=0.003) .{ }^{8}$ Both these outcomes were significantly reduced when considered as individual end-points $(3.7 \%$ vs $5.4 \%, p=0.038$ for death; $9.2 \%$ vs $12.7 \%, p=0.0005$ for MI). Hospital readmissions were also significantly reduced over two years in the invasive group $(44.8 \%$ vs $64.5 \%, p<0.001)$. An important observation is that $43 \%$ of the conservative group had undergone some form of revascularisation within one year.

\section{TACTICS-TIMI 18}

In TACTICS-TIMI 18, 2,220 patients with NSTE ACS recruited between 1997 and 1999 were treated with intravenous tirofiban for 48 hours and then randomised to medical or invasive treatment. ${ }^{9}$ Of the revascularised patients, $68 \%$ underwent angioplasty and stenting (percutaneous coronary intervention (PCI)). The primary end-point of death, non-fatal $\mathrm{MI}$, or rehospitalisation for ACS at six months occurred significantly less frequently in the early invasive group ( $15.9 \%$ vs $19.4 \%, p=0.025$ ). Specifically, there was an absolute reduction of $10 \%$ in those patients with elevated TnT $(>0.1 \mathrm{ng} / \mathrm{ml})$.

\section{RITA 3}

The RITA 3 trial recruited 1,810 patients with ACS between 1997 and 2001. The primary end-point, death, non-fatal MI or refractory angina at four months, ${ }^{10}$ occurred in significantly fewer patients in the early invasive group than in the early conservative group ( $9.6 \%$ vs $14.5 \%$, relative risk (RR) $0.66,95 \%$ confidence interval (CI) $0.51-0.85, p=0.001$ ). This reduction was maintained at one year

\section{Key Points}

Non-ST segment elevation (NSTE) acute coronary syndromes (ACS) account for the majority of coronary care unit admissions. Registry data reveal a $12 \%$ rate of death or myocardial infarction six months after such admission, and a $30 \%$ rate of death, MI, refractory angina or readmission to hospital for unstable angina

The invasive cardiologist expects to be offered three categories of patient with ACS for angiography and revascularisation: patients with (1) ongoing pain or ECG changes, (2) elevated troponin levels ( $\mathrm{TnT} \leqslant 0.05 \mathrm{ng} / \mathrm{ml}$ ), (3) ST depression on admission ECG

Contemporary literature unequivocally demonstrates prognostic benefit for early revascularisation in patients with NSTE ACS deemed at high risk by virtue of the factors listed above

It is important to note that invasive investigation and treatment prognostic benefit is apparently achieved in the last two of the categories of patient who should undergo early (ie inpatient) even if their angina settles with medical treatment

$(p=0.003)$. The difference was due to a reduction in refractory angina $(\mathrm{RR} 0.56$ at one year, $p=0.0002$ ) with no significant decrease in death or MI at four, 12 or 24 months. In particular, angina $(p<0.001)$ and use of anti-anginal medication $(p<0.0001)$ were significantly lower in the invasive group.

\section{Summary of the trial evidence}

The historical trials, TIMI IIIB and VANQWISH, failed to demonstrate a difference in outcome between patients managed with early invasive and conservative strategies.

By contrast, the contemporary trials, FRISC II, TACTICS-TIMI 18 and RITA 3, all reported that early invasive assessment and subsequent revascularisation of ACS patients identified to be at higher risk led to improvements in symptomatic and prognostic outcome compared with medically treated patients. This represents the foundation for the current strategy of transfer of such patients to the care of invasive cardiologists and does not depend upon ongoing symptoms.

The increasing rates of stent deployment $(61 \%$ of PCI cases in the invasive arm of FRISC II, $88 \%$ in RITA 3 ) and periprocedural GPIIb/IIIa inhibitor use (10\% in FRISC II, 25\% in RITA 3, 94\% in TACTICS-TIMI 18) in clinical practice were paralleled by the trials and have contributed to the reduction in
PCI-related MI in both settings. ${ }^{7,9,10}$ It is likely that the benefit of PCI in these studies is therefore underestimated. In contemporary practice, both stents and GPIIb/IIIa inhibitors are used in over $90 \%$ of these ACS patients.

\section{Practical difficulties and ongoing controversy}

Analysis of the contemporary literature therefore unequivocally demonstrates prognostic benefit for early revascularisation in patients with NSTE ACS deemed at high risk by virtue of ongoing ischaemia, elevated Tn or ST depression. Importantly, patients in the last two categories apparently derive prognostic benefit even if their angina settles with medical treatment. This is the basis for the recommendation that they should be treated as inpatients, but raises the practical issue of how to treat all such patients within a reasonable amount of time and, just as important, how to do so in an equitable manner. It is ironic that most such patients treated by PCI go home the next day.

Patients with ACS who fulfil the criteria for angiography are kept waiting significantly longer if they are admitted to a feeder district general hospital (DGH) rather than to a hospital with revascularisation facilities (13 days vs five days, $p<0.0005)^{11}$ (a good example of postcode medicine). The data suggest that the ideal time to achieve angio- 
graphy and revascularisation is within 72 hours of presentation.

The optimal timing of PCI in NSTEACS patients is in itself controversial. It has been suggested that the benefit of the early invasive strategy in TACTICS-TIMI 18 was due to the effect of a median of 25 hours' treatment with a GPIIb/IIIa inhibitor prior to PCI. ${ }^{9}$ The question of whether a 'cooling off' period prior to PCI might reduce procedure-related events was addressed in the ISAR-COOL study (American Heart Association, Chicago, 2002). In this study, 410 patients with NSTE ACS scheduled to undergo PCI were randomised to either PCI immediately (mean time 2.4 hours) or to a 'cooling off' period in which they were treated with aspirin, clopidogrel, tirofiban and heparin for 72-120 hours before the procedure was conducted. The primary end-point of death or non-fatal MI at 30 days was significantly reduced in the early PCI group ( $5.9 \%$ vs $11.6 \%, p=$ 0.04). The excess events in the 'cooling off' arm were MIs occurring before catheterisation - suggesting that delaying PCI is counterproductive.

Table 1. American College of Cardiology/American Heart Association class 1 recommendations for an early invasive or early conservative strategy in the management of nonST segment elevation acute coronary syndromes.

1 An early invasive strategy in patients with UA/NSTEMI without serious comorbidity who have any of the following high-risk indicators (Level of Evidence: $A$ ):
(a) Recurrent angina/ischaemia at rest or with low-level activities despite intensive anti-ischaemic therapy
(b) Elevated TnT or Tnl
(c) New or presumably new ST segment depression
(d) Recurrent angina/ischaemia with CHF symptoms, an S3 gallop, pulmonary oedema, worsening rales, or new or worsening MR
(e) High risk findings on non-invasive stress testing
(f) Depressed LV systolic function (eg EF $<40 \%$ on non-invasive study)
(g) Haemodynamic instability
(h) Sustained ventricular tachycardia
(i) $\mathrm{PCl}$ within 6 months
(j) Prior $\mathrm{CABG}$

2 In the absence of any of these findings, either an early conservative or an early invasive strategy may be offered in hospitalised patients without contraindications for revascularisation (Level of Evidence: B).

$\mathrm{CABG}=$ coronary artery bypass graft; $\mathrm{CHF}=$ congestive heart failure; $\mathrm{EF}=$ ejection fraction; $\mathrm{LV}=$ left ventricular; $\mathrm{MR}=$ mitral regurgitation; NSTEMI = non-ST elevation myocardial infarction; $\mathrm{PCl}=$ percutaneous coronary intervention; $\mathrm{TnI}=$ troponin $\mathrm{I} ; \mathrm{TnT}=$ troponin $\mathrm{T} ; \mathrm{UA}=$ unstable angina. the benefit of an early invasive strategy was not statistically significant $(7.4 \%$ vs $8.5 \%, p=0.59)$. There were similar results in TACTICS-TIMI 18.

It is useful to establish that only certain subgroups of patient benefit from the early invasive approach, but risk stratification could possibly be further refined in the future. ${ }^{13}$ Even patients with ST depression and Tn elevation have event rates of under $30 \%$. If patients who will have further events could be identified, the intolerable pressure that this (appropriate) management puts upon DGH beds and revascularisation services could be relieved.

\section{Other risk markers}

A number of other markers have been shown to be related to the risk of further adverse cardiac events after NSTE ACS and may indicate ways of improving risk stratification.

C-reactive protein. In the FRISC II trial, for example, the probability of death at five months increased with increasing tertile of fibrinogen $(1.6 \%$ vs $4.6 \%$ vs $6.9 \%, p=0.005)$ and $\mathrm{C}$-reactive protein (CRP) $(2.2 \%$ vs $3.6 \%$ vs $7.5 \%, p=$ $0.003) .{ }^{14}$ Further, CRP remained an independent predictor of death after 37 months follow-up. ${ }^{15}$ This is consistent with data from GUSTO IV, in which CRP independently predicted death, and 30-day mortality increased with quartiles of CRP $(2.0 \%, 3.3 \%, 3.9 \%$ and $6.3 \%$, $p<0.001) .{ }^{16}$

CD40 ligand. Recently, the CAPTURE study found that soluble CD40 ligand, a marker of platelet activation, predicted risk of death or MI among 1,088 ACS patients and in a more diverse group of patients presenting with acute chest pain. ${ }^{17}$

In the future there may be models for risk stratification involving a combination of markers that represent different levels of the pathophysiological cascade of NSTE ACS. These markers may facilitate increasingly effective targeting of medical and invasive interventions.

Currently, optimal management of the three categories of patients referred to above who are under the care of general 
physicians determines that they should be admitted and transferred for inpatient coronary angiography and revascularisation. For many patients, this is independent of whether or not they have ongoing symptoms. Not to do so puts them at high risk of a major adverse cardiac event.

\section{Conclusions}

NSTE ACS is associated with considerable morbidity and mortality, with a $30 \%$ rate of death, MI, refractory angina or readmission to hospital for unstable angina at six months. Contemporary trials show that the risk of further adverse cardiac events can be reduced by an early revascularisation strategy. The current evidence base determines that patients in the following categories benefit prognostically from early (ie inpatient) angiography and revascularisation:

- ongoing evidence of ischaemia

- elevated Tn regardless of ongoing symptoms

- ST depression regardless of ongoing symptoms.

In clinical practice, patients with ongoing chest pain self select for early coronary angiography. For other patients, their risk for further adverse cardiac events can be stratified on admission by Tn, ST segment changes and TIMI risk score. Medium and high risk patients benefit the most from an invasive strategy, while low risk patients achieve similar outcomes with either an early invasive or an early conservative strategy (Table 1). ${ }^{18}$ For patients undergoing PCI, the treatment is extremely efficient, most going home the following day. More resources are needed to reduce the time it takes to get these patients to the catheterisation laboratory with an interventional cardiologist.

\section{References}

1 Collinson J, Flather MD, Fox KA, Findlay I et al. Clinical outcomes, risk stratification and practice patterns of unstable angina and myocardial infarction without ST elevation: Prospective Registry of Acute Ischaemic Syndromes in the UK (PRAIS-UK). Eur Heart J 2000;21:1450-7.

2 Falk E, Shah PK, Fuster V. Coronary plaque disruption. Review. Circulation 1995;92: 657-71.

3 Archbold RA, Curzen NP. Issues relating to clopidogrel use in hospital practice. $\mathrm{Br} J$ Cardiol 2002;9(Suppl 8):S13-19.

4 Effects of tissue plasminogen activator and a comparison of early invasive and conservative strategies in unstable angina and nonQ-wave myocardial infarction. Results of the TIMI IIIB Trial. Thrombolysis in Myocardial Ischemia. Circulation 1994;89: 1545-56.

5 Anderson HV, Cannon CP, Stone PH, Williams DO et al. One-year results of the Thrombolysis in Myocardial Infarction (TIMI) IIIB clinical trial. A randomized comparison of tissue-type plasminogen activator versus placebo and early invasive versus early conservative strategies in unstable angina and non-Q wave myocardial infarction. J Am Coll Cardiol 1995; 26:1643-50.

6 Boden WE, O'Rourke RA, Crawford MH, Blaustein AS et al. Outcomes in patients with acute non-Q-wave myocardial infarction randomly assigned to an invasive as compared with a conservative management strategy. Veterans Affairs Non-Q-Wave Infarction Strategies in Hospital (VANQWISH) Trial Investigators. N Engl J Med 1998;338:1785-92.

7 Invasive compared with non-invasive treatment in unstable coronary-artery disease: FRISC-II prospective randomised multicentre study. FRagmin and Fast Revascularisation during InStability in Coronary artery disease Investigators. Lancet 1999;354:708-15.

8 Lagerqvist B, Husted S, Kontny F, Nashund $\mathrm{U}$ et al; Fast Revascularization during InStability in Coronary Artery Disease-II Investigators. A long-term perspective on the protective effects of an early invasive strategy in unstable coronary artery disease: two-year follow-up of the FRISC-II invasive study. J Am Coll Cardiol 2002;40:1902-14.

9 Cannon CP, Weintraub WS, Demopoulos LA, Vicari R et al; TACTICS (Treat Angina with Aggrastat and Determine Cost of Therapy with an Invasive or Conservative Strategy)-Thrombolysis In Myocardial Infarction 18 Investigators. Comparison of early invasive and conservative strategies in patients with unstable coronary syndromes treated with glycoprotein IIb/IIIa inhibitor tirofiban. N Engl J Med 2001;344:1879-87.

10 Fox KA, Poole-Wilson PA, Henderson RA, Clayton TC et al; Randomized Intervention Trial of unstable Angina (RITA)
Investigators. Interventional versus conservative treatment for patients with unstable angina or non-ST-elevation myocardial infarction: the British Heart Foundation RITA 3 randomised trial. Lancet 2002; 360:743-51

11 Miller C, Lipscomb K, Curzen N. Are district general hospital patients with unstable angina at a disadvantage? Postgrad Med J 2003;79:93-8.

12 Lindahl B, Diderholm E, Lagerqvist B, Venge $\mathrm{P}$ et al; FRISC II (Fast Revascularization during InStability in CAD) Investigators. Mechanisms behind the prognostic value of troponin $\mathrm{T}$ in unstable coronary artery disease: a FRISC II substudy. J Am Coll Cardiol 2001;38:979-86.

13 Smith E, Fath-Ordoubadi F, Curzen N. Unstable angina: the case for selective aggression. Br J Cardiol 2002;9:251-4.

14 Toss H, Lindahl B, Siegbahn A, Wallenstein L. Prognostic influence of increased fibrinogen and C-reactive protein levels in unstable coronary artery disease. FRISC Study Group (Fragmin during Instability in Coronary Artery Disease). Circulation 1997;96:4204-10.

15 Lindahl B, Toss H, Siegbahn A, Venge P, Wallentin L. Markers of myocardial damage and inflammation in relation to long-term mortality in unstable coronary artery disease. FRISC Study Group. Fragmin during Instability in Coronary Artery Disease. N Engl J Med 2000;343:1139-47.

16 James SK, Armstrong P, Barnathan E, Califf $\mathrm{R}$ et al; GUSTO-IV-ACS Investigators. Troponin and C-reactive protein have different relations to subsequent mortality and myocardial infarction after acute coronary syndrome: a GUSTO-IV substudy. J Am Coll Cardiol 2003;41:916-24.

17 Heeschen C, Dimmeler S, Hamm CW, van den Brand MJ et al. Soluble CD40 ligand in acute coronary syndromes. $N$ Engl J Med 2003;348:1104-11.

18 Braunwald E, Antman EM, Beasley JW, Califf RM et al. ACC/AHA guideline update for the management of patients with unstable angina and non-ST-segment elevation myocardial infarction-2002: summary article: a report of the American College of Cardiology/American Heart Association Task Force on Practice Guidelines (Committee on the Management of Patients With Unstable Angina). Circulation 2002; 106:1893-1900. 